А. В. Игнатенко, А. А. Масехнович

Белорусский государственный технологический университет

\title{
БИОСОРБЦИОННЫЕ, БИОКОАГУЛЯЦИОННЫЕ СВОЙСТВА АКТИВНОГО ИЛА И ИЗМЕНЕНИЕ ТОКСИЧНОСТИ СТОЧНЫХ ВОД В ПРОЦЕССЕ ИХ БИОЛОГИЧЕСКОЙ ОЧИСТКИ
}

Рассмотрены биосорбционные, биокоагуляционные свойства активного ила и его способность связывать ионы тяжелых металлов $\mathrm{Fe}^{\text {общ }} \mathrm{Cr}^{6+}$, а также снижать уровень взвешенных и токсичных веществ в сточных водах в процессе их биологической очистки на городских очистных сооружениях.

Анализ биокоагуляционных свойств активного ила показал, что он обладает хорошей способностью агрегировать коллоидные и грубодисперсные примеси сточных вод и снижать их концентрации в 2-5 раз в зависимости от соотношения активный ил : сточные воды на стадии механической очистки в первичных отстойниках.

Отмечена важная роль сорбционных свойств активного ила в детоксикации сточных вод по коридорам аэротенка. Отработанный активный ил сохранял до $30 \%$ своей максимальной сорбционной емкости связывания тяжелых металлов. После обработки активного ила ЭДТА его сорбционная емкость увеличивалась в 2-3 раза по отношению к ионам Fебе.

Биотестирование токсичности сточных вод по коридорам аэротенка свидетельствует о том, что показатели индекса токсичности сточных вод и остаточной сорбционной емкости активного ила в аэротенке коррелируют между собой, что может быть использовано для контроля процесса детоксикации сточных вод.

Ключевые слова: биологическая очистка, сточные воды, взвешенные вещества, индекс токсичности, биотестирование, активный ил, тяжелые металлы.

Для цитирования: Игнатенко А. В., Масехнович А. А. Биосорбционные, биокоагуляционные свойства активного ила и изменение токсичности сточных вод в процессе их биологической очистки // Труды БГТУ. Сер. 2, Химические технологии, биотехнологии, геоэкология. 2021. № 1 (241). С. 63-68.

\author{
A. V. Ignatenko, A. A. Masechnovich \\ Belarusian State Technological University
}

\section{BIOSORPTION, BIOCOAGULATION PROPERTIES OF ACTIVE SLUDGE AND WASTE WATERS TOXICITY CHANGING DURING THEIR BIOLOGICAL TREATMENT}

The biosorption and biocoagulation properties of active sludge and its ability to adsorb the ions of heavy metals: $\mathrm{Fe}^{\text {total }}, \mathrm{Cr}^{6+}$ and also to decrease the concentrations of suspended particles and water toxicity were considered in the processes of biological treatment of waste waters at city sewage treatment plant.

Analyses of biocoagulation properties of active sludge showed that it has a good ability to aggregate colloidal and rude dispersed particles in waste waters and to decrease of their concentration in 2-5 times depending from the relation of active sludge : waste water at the stage of mechanical treatment in primary settlers.

It was marked the important role of biosorption properties of active sludge in waste water detoxication on corridors of aerotank. Worked up active sludge possessed $30 \%$ of its maximal sorption ability. After EDTA treatment its sorption capacity to $\mathrm{Fe}^{\text {total }}$ increased in 2-3 times.

Biotesting of waste waters toxicity on corridors of aerotank showed a good correlation between index of toxicity waste waters and the rest sorption capacity of active sludge on the stages of biological treatment.

Key words: biological treatment, waste waters, sedimental particals, toxicity index, biotesting, active sludge, heavy metals.

For citation: Ignatenko A. V., Masechnovich A. A. Biosorption, biocoagulation properties of active sludge and waste waters toxicity changing during their biological treatment. Proceedings of BSTU, issue 2, Chemical Engineering, Biotechnologies, Geoecology, 2021, no. 1 (241), pp. 63-68 (In Russian).

Введение. Детоксикация сточных вод и иловых осадков, загрязненных химически опасными веществами, является одной из актуальных задач водоочистки, повышения экологической безопасности окружающей среды и практического использования осадков сточных вод $[1,2]$.

Среди основных токсичных веществ, присутствующих в сточных водах, выделяют тяжелые 
металлы, которые не разрушаются в процессе очистки, а циркулируют между свободным и связанным состояниями, меняя свою активность.

Анализ распределения ионов железа по фракциям частиц в сточных водах, отобранных из первичного отстойника Минской очистной

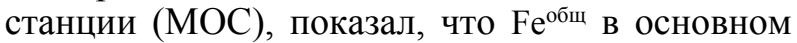
находится связанным в молекулярно-коллоидной и коллоидно-суспензионной формах $(68,1 \%)$ и образует комплексы с органическими и неорганическими веществами [3]. Содержание свободных ионов железа $(14,7 \%)$ было значительно меньше, чем в связанной форме. Остальная доля железа приходилась на мелко-, среднеи крупнодисперсные частицы $(17,3 \%)$, частично осаждаемые в процессе механической очистки сточных вод в первичном отстойнике.

При анализе индекса токсичности сточных вод на разных стадиях их очистки на МOC-1 и МОС-2 было установлено, что основную нагрузку по детоксикации сточных вод берет на себя активный ил аэротенка, биосорбционные и биодеструктивные свойства которого уменьшали токсичность сточных вод на выходе очистных сооружений до безопасных значений [3].

Повышение концентрации тяжелых металлов в возвратных активных илах негативно сказывается на качестве очистки сточных вод [1].

Способность микроорганизмов активного ила сорбировать и аккумулировать тяжелые металлы предопределяет наличие их значительных концентраций в твердой фазе осадков даже при малой концентрации в очищаемой воде.

Основная часть. Цель работы - анализ взаимосвязи изменений биосорбционных и биокоагуляционных свойств активного ила и токсичности сточных вод в процессе их биологической очистки.

В работе использовали следующее оборудование: аналитические весы RADWAG AS 220/C/2/N, спектрофотометр SPECORD M40 (Германия), микровизор Levenhuk DTX 500 LCD, дистиллятор A-10, автоматические дозаторы жидкости AW-2-2000 с наконечниками HTL Disposable Tips, СВЧ-печь Samsung CE935GR, центрифугу Hettich модель EBA-20, фильтрационное устройство SWINNEX-47 MILLIPORE и мембранные фильтры капроновые микропористые «ХИЙУ КАЛУР» (Эстония) с диаметром микропор 0,2 мкм, бумажные фильтры (белая лента). $\mathrm{pH}$ растворов измеряли на $\mathrm{pH}$-метре Hanna pH 211.

В качестве объектов исследования служили образцы сточных вод (СВ), отобранных в первичном, вторичном отстойниках, аэротенке и образцы активного ила (АИ), взятые из четырех коридоров аэротенка и иловой камеры MOC-1.
Отбор проб осуществляли в соответствии с [4]. Влажность образцов АИ определяли методом высушивания до постоянной массы и взвешивания.

Для проведения исследований применяли водные растворы солей тяжелых металлов (ТМ): бихромата калия, сульфата железа; кислоты: ортофосфорную, сульфосалициловую, серную; растворы аммиака, хлорида аммония, 1,5-дифенилкарбазида, а также растворы ЭДТА, приготовленные в концентрациях $10^{-1}-10^{-5} \mathrm{M}$.

В качестве СПАВ использовали лауретсульфат натрия производства «ХимАльянс» (РФ) в диапазоне концентраций 0,005-0,500\%.

Оптимальную дозу АИ для коагуляции частиц сточных вод определяли по остаточному количеству взвешенных веществ, фильтрованием через бумажный фильтр, его высушиванием до постоянной массы и взвешиванием. Для этого в семь мерных цилиндров помещали по $150 \mathrm{~cm}^{3}$ сточной воды, с известным содержанием взвешенных веществ, добавляли в нее 0 $70 \mathrm{~cm}^{3}$ активного ила, тщательно перемешивали и отстаивали 30 мин. Затем отбирали по $50 \mathrm{~cm}^{3}$ надосадочной жидкости из каждого цилиндра и проводили измерение в ней остаточного количества взвешенных веществ.

Концентрации ионов $\mathrm{Fe}^{\text {общ }}, \mathrm{Cr}^{6+}$ в $\mathrm{CB}$ и вытяжках АИ измеряли методами фотометрии. При определении общего содержания железа использовали его реакцию с сульфосалициловой кислотой в щелочной среде. Содержание хрома определяли по реакции с 1,5-дифенилкарбазидом в кислой среде [5].

Используя стандартные растворы бихромата калия и сернокислого железа в дистиллированной воде, приготавливали калибровочные растворы, содержащие 0,005-2,000 мг/ $\mathrm{cm}^{3} \mathrm{Cr}^{6+}$ или $\mathrm{Fe}^{\text {общ }}$, и измеряли величину их оптической плотности $D_{540}$ и $D_{425}$, соответственно, от концентрации ТМ.

Для анализа содержания железа в сточных водах или в водных вытяжках активного ила $50 \mathrm{~cm}^{3}$ проб пропускали через бумажный фильтр в мерную колбу на $100 \mathrm{~cm}^{3}$. К фильтрату последовательно приливали при перемешивании $1 \mathrm{~cm}^{3}$ раствора аммиака, $2 \mathrm{~cm}^{3}$ раствора хлорида аммония, $2 \mathrm{~cm}^{3}$ раствора сульфосалициловой кислоты. Доводили объем до метки дистиллированной водой, измеряли $D_{425}$ и определяли концентрацию $\mathrm{Fe}^{\text {общ } п о ~ к а л и б р о в о ч н о м у ~ г р а ф и к у . ~}$

В случае определения $\mathrm{Cr}^{6+}$ в сточных водах анализируемые растворы отфильтровывали через бумажный фильтр. Фильтрат объемом $95 \mathrm{~cm}^{3}$ помещали в мерные колбы на $100 \mathrm{~cm}^{3}$, затем в каждую колбу добавляли $1 \mathrm{~cm}^{3}$ раствора серной кислоты, 0,3 см с $^{3}$ ортофосфорной кислоты, $2 \mathrm{~cm}^{3}$ раствора 1,5-дифенилкарбазида, доводили 
до метки дистиллированной водой и измеряли оптическую плотность при 540 нм.

По калибровочному графику определяли концентрацию $\mathrm{Cr}^{6+}$.

Оценку остаточной емкости связывания ТМ активным илом проводили по отношению к $\mathrm{Fe}^{\text {общ }}$ и выражали в относительных величинах:

$$
a=\frac{A_{\mathrm{ocT}}}{A_{\max }} \cdot 100 \%,
$$

где $A_{\text {ост }}, A_{\max }$ - адсорбционная емкость связывания ТМ активным илом соответственно до и после его обработки ЭДТА.

При определении $A_{\text {ост }}$ к 50 мл отобранного АИ добавляли известную концентрацию ионов железа, выдерживали 2 ч, центрифугировали при 6000 об/мин в течение 10 мин. Рассчитывали количество связанного железа по разности концентраций в надосадочной жидкости до и после внесения ТМ.

Величину $A_{\max }$ находили после обработки АИ комплексоном ЭДТА, удаляющим подвижные формы большинства хелатно связанных ТМ [6]. Для этого к 50 мл АИ добавляли 0,05 г ЭДТА, выдерживали при перемешивании 1 ч, центрифугировали при 6000 об/мин на протяжении 10 мин, надосадочную жидкость доводили дистиллированной водой до первоначального объема и проводили анализ сорбционных свойств АИ.

Анализ связывания ионов железа активным илом, не обработанным и обработанным ЭДТА, выполняли при $20^{\circ} \mathrm{C}$ в соответствии с уравнением изотермы мономолекулярной сорбции Ленгмюра [3]:

$$
A=A_{\infty} \cdot \frac{K \cdot C}{1+K \cdot C},
$$

где $A, A_{\infty}$ - соответственно текущая и максимальная статическая емкость связывания; $K$ константа связывания; $C$ - равновесная концентрация ТМ в растворе.

Тогда

$$
A=\Delta C \cdot \frac{V}{m},
$$

где $\Delta C$ - разность текущей и равновесной концентраций ТМ, моль/л; $V$ - объем раствора солей металла, л; $m$ - масса активного ила, г.

После преобразования в обратных координатах строили график зависимости:

$$
\frac{1}{A}=\frac{1}{A_{\infty}}+\frac{1}{A_{\infty} \cdot K \cdot C}
$$

и определяли параметры $K$ и $A_{\infty}$.

Биотестирование токсичности образцов проводили на модельных растворах, вытяжках АИ и СВ, отобранных на MOC-1.
Контроль за содержанием токсичных веществ в анализируемых средах осуществляли путем оценки их влияния на выживаемость тесткультуры клеток при $20^{\circ} \mathrm{C}$.

В качестве тест-объекта для биотестирования токсичности использовали клетки микроводоросли Euglena gracilis из коллекции кафедры биотехнологии БГТУ. Выращивание клеток тест-культуры осуществляли в среде ЛозиноЛозинского (контроль).

Для оценки выживаемости тест-культуры к $0,9 \mathrm{~cm}^{3}$ анализируемой или контрольной среды добавляли $0,1 \mathrm{~cm}^{3}$ клеток E. gracilis, образцы выдерживали сутки при $20^{\circ} \mathrm{C}$ на свету и определяли выживаемость клеток по сохранению их подвижности.

Подсчет клеток вели в 10 разных полях зрения, рассчитывая средние значения и их доверительные интервалы [7].

Индекс токсичности (ИТ) образцов определяли по формуле

$$
\text { ИТ }=\frac{n_{k}-n_{i}}{n_{k}} \cdot 100 \%,
$$

где $n_{k}, n_{i}$ - средние значения количества клеток в водной среде соответственно в отсутствии и присутствии токсикантов.

Полученные результаты обрабатывали статистически, используя приложение Microsoft Excel.

Наряду с ТМ сточные воды городских очистных сооружений также сильно загрязнены взвешенными веществами.

Исходное количество взвешенных веществ $\mathrm{CB}$ на входе в первичный отстойник MOC-1 398 мг/дм ${ }^{3}$, в самом отстойнике -238 мг/дм ${ }^{3}$.

Предельно допустимое значение данного показателя на выходе очистных сооружений в водах, сбрасываемых в окружающую среду, составляет 20-30 мг/дм ${ }^{3}$ [8].

Для наиболее полной очистки СВ в аэротенках большая часть взвешенных веществ должна удаляться на этапе механической очистки, поэтому необходимо повышать эффективность предварительной очистки СВ от взвешенных веществ. Для этого предложено использовать часть избыточного АИ для дополнительного осаждения взвешенных частиц СВ в первичных отстойниках.

На рис. 1 приведено изменение концентрации взвешенных веществ в $\mathrm{CB}$, отобранных из первичного отстойника, в зависимости от объемного соотношения АИ : $\mathrm{CB}$.

Как видно из рис. 1, увеличение соотношения АИ : СВ с 0 до 0,4 позволяет снизить содержание взвешенных частиц в СВ первичного отстойника с 238 до 50 мг/дм³ 


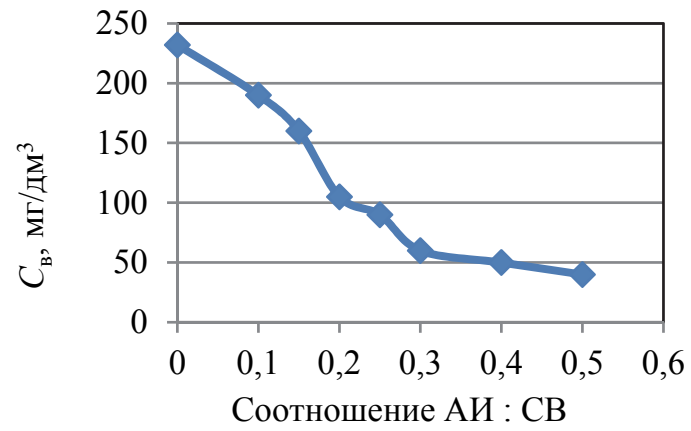

Рис. 1. Зависимость концентрации взвешенных частиц первичного отстойника от объемного соотношения $\mathrm{A} И: \mathrm{CB}$

Полученные результаты указывают на хорошие биокоагуляционные свойства АИ и его способность агрегировать коллоидные и грубодисперсные примеси СВ первичного отстойника, что улучшит качество очистки сточных вод в аэротенке.

Для анализа сорбционных свойств АИ была изучена его способность связывать ионы отдельных ТМ. На рис. 2 приведена кинетика адсорбции активным илом ионов железа и хрома в модельных условиях.

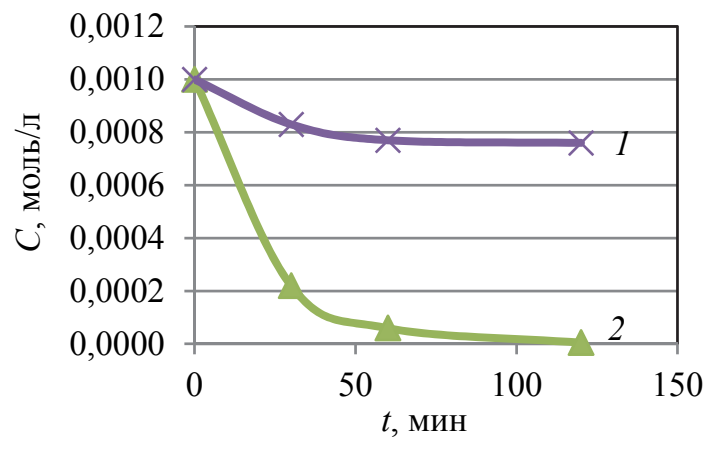

Рис. 2. Кинетика адсорбции ионов тяжелых металлов активным илом при $20^{\circ} \mathrm{C}, \mathrm{pH} 7$ :

$$
1-\mathrm{Cr}^{6+} ; 2-\mathrm{Fe}^{\text {общ }}
$$

Как видно из рис. 2 , равновесная концентрация связывания тяжелых металлов устанавливается в течение 1-2 ч. Максимальное связывание ТМ активным илом для ионов железа было выше, чем для ионов хрома.

Поскольку отработанный АИ уже загрязнен TM, для определения его $A_{\max }$ проводили обработку ила комплексоном ЭДТА.

На рис. 3 показаны изменения величины относительной сорбционной емкости активного ила, отобранного из иловой камеры, от равновесной концентрации ионов железа до и после обработки ила ЭДТА.

Из рис. 3 видно, что после детоксикации активного ила ЭДТА количество сорбированного железа увеличивается примерно в 3 раза по сравнению с необработанным АИ.

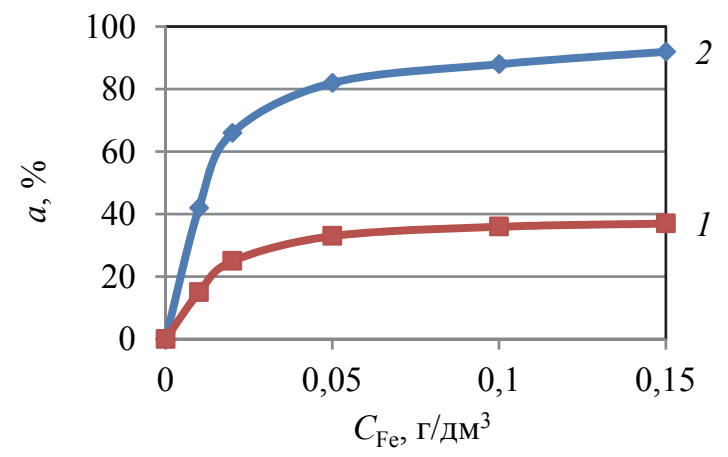

Рис. 3. Изотермы адсорбции ионов железа активным илом при $20^{\circ} \mathrm{C}, \mathrm{pH} 7$ :

1 - исходным АИ; 2 - АИ, обработанным ЭДТА

Как известно, ЭДТА способен образовывать устойчивые комплексные соединения с большинством катионов тяжелых металлов как в кислой, так и в щелочной среде, поскольку комплексон содержит 4 кислотных и 2 основных центра [7].

Проведенные модельные исследования показали, что АИ является хорошим сорбентом ТМ и может быть использован в процессах дополнительной очистки и детоксикации СВ.

Для определения эффективности детоксикации $\mathrm{CB}$ активным илом в процессе их биологической очистки был проведен анализ связывания ионов железа активным илом в 1-4 коридорах аэротенка. Полученные результаты приведены на рис. 4.

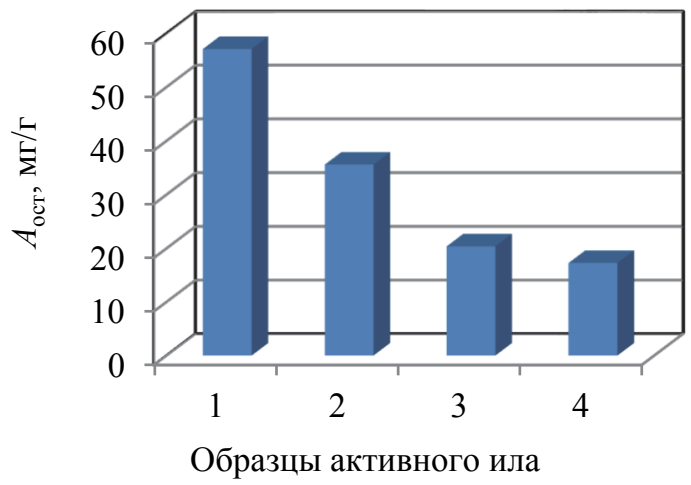

Рис. 4. Остаточная емкость связывания ионов железа образцами активного ила, отобранными в 1-4 коридорах аэротенка

Наблюдаемое максимальное значение $A_{\text {ост }}$ связывания ионов железа активным илом в 1-м коридоре аэротенка согласуется с протекающими в нем процессами регенерации АИ, при которых он восстанавливает свои свойства [2].

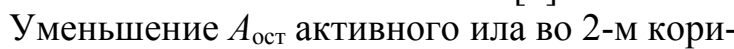
доре аэротенка вызвано адсорбцией легко окисляемых веществ СВ, поступающих сюда из первичного отстойника. 
В 3-м коридоре сооружения дополнительно сорбируются и разрушаются трудно окисляемые вещества.

В 4-м коридоре аэротенка завершаются процессы биодеструкции медленно окисляемых веществ, активный ил голодает и начинаются процессы его отмирания и ассоциации.

Рассчитанное по формуле (1) значение величины $a$ активного ила на выходе из аэротенка составило $30 \%$, что указывает на достаточно высокую остаточную сорбционную емкость АИ по отношению к ТМ и на возможность его использования для дополнительной очистки и детоксикации СB.

Дальнейшая часть работы была связана с анализом детоксикации сточных вод активным илом в процессе биологической очистки СВ в аэротенке.

На рис. 5 приведены результаты изменения индекса токсичности СВ по коридорам аэротенка.

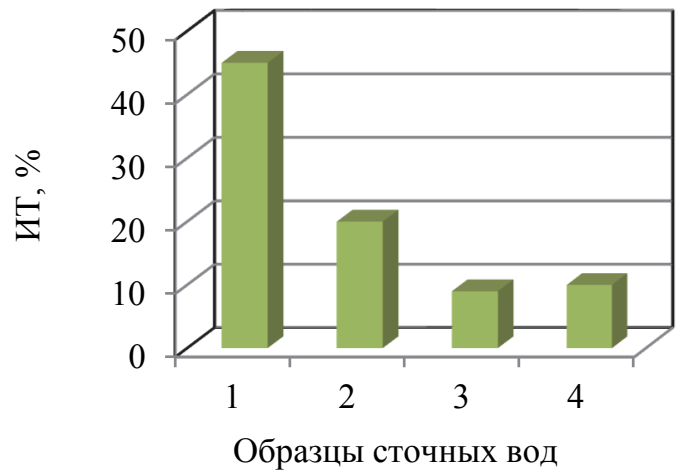

Рис. 5. Изменение индекса токсичности сточных вод по 1-4 коридорам аэротенка

Из рис. 5 видно, что максимальное значение ИТ сточных вод наблюдается в 1-м коридоре аэротенка и снижается далее по сооружению так же, как и остаточная адсорбционная емкость активного ила (рис. 4).

Изменение показателей $A_{\text {ост }}$ активного ила и ИТ сточных вод в аэротенке хорошо коррелирует между собой. Коэффициент корреляции составил $98,4 \%$.
Это позволяет контролировать процесс детоксикации сточных вод не только по остаточной адсорбционной емкости активного ила, но и по индексу токсичности сточных вод.

Заключение. Проведенная в данной работе характеристика биосорбционных, биокоагуляционных свойств активного ила показала, что он является достаточно хорошим сорбентом тяжелых металлов и биокоагулянтом коллоидных и взвешенных частиц сточных вод.

При анализе остаточной сорбционной емкости активного ила, отработанного в аэротенке, установлено, что по отношению к связыванию ионов железа АИ сохраняет порядка $30 \%$ своей адсорбционной способности.

Дополнительная обработка активного ила ЭДТА повышает его остаточную сорбционную емкость в 2-3 раза и позволяет дополнительно применять его в процессах очистки и детоксикации сточных вод.

Использование активного ила в качестве биокоагулянта и биосорбента на этапе механической очистки сточных вод в первичных отстойниках снижало содержание в них взвешенных частиц в 2-5 раз при изменении соотношения АИ : СВ от 0,2 до 0,5. При этом уровень токсичности сточных вод после первичного отстойника снижался в 2-3 раза.

Применение части избыточного активного ила в качестве биосорбента и биокоагулянта является целесообразным и позволяет повысить качество очистки сточных вод городских очистных сооружений.

Несмотря на то, что использование отработанного активного ила менее эффективно, чем обработанного ЭДТА, в условиях реального производства его применение может быть более экономичным вариантом для очистки сточных вод, не требующим дополнительных затрат на реагенты и специальное оборудование.

Наличие корреляции между остаточной сорбционной емкостью активного ила и уровнем токсичности сточных вод может быть использовано для контроля процесса детоксикации сточных вод.

\section{Список литературы}

1. Жмур Н. С. Технологические и биохимические процессы очистки сточных вод на сооружениях с аэротенками. М.: АКВАРОС, 2003. 512 с.

2. Марцуль В. Н. Нормативное правовое регулирование обращения с осадками очистных сооружений канализации // Современные тенденции в развитии водоснабжения и водоотведения: материалы Междунар. конф., посвящ. 145-летию УП «Минскводоканал», Минск, 13-14 февр. 2019 г.: в 2 ч. / Белорус. гос. технол. ун-т. Минск, 2019. Ч. 2. С. 195-200.

3. Игнатенко А. В. Биосорбционно-биокоагуляционная детоксикация сточных вод микроорганизмами активного ила // Труды БГТУ. 2015. № 4 : Химия, технология орган. в-в и биотехнология. C. 262-266.

4. Методические указания по отбору проб для анализа сточных вод: ПНД Ф 12.15.1-08. М.: ФБУ ФЦАО, 2015.45 c. 
5. Марченко 3., Бальцежак М. Методы спектрофотометрии в УФ и видимой областях в неорганическом анализе. М.: Бином: Лаборатория знаний, 2007. 714 с.

6. Климов Е. С., Бузаева М. В. Природные сорбенты и комплексоны в очистке сточных вод. Ульяновск: УлГТУ, 2011.201 с.

7. Игнатенко А. В. Пробоподготовка и биотестирование токсичности иловых осадков сточных вод // Химическая безопасность. 2018. Т. 2, № 2. С. 251-271.

8. О некоторых вопросах нормирования сбросов химических и иных веществ в составе сточных вод: постановление М-ва природных ресурсов и охраны окружающей среды Респ. Беларусь от 26.05.2017 № 16 // Национальный правовой Интернет-портал Республики Беларусь. URL: https://pravo.by/upload/docs/op/W21732141_1497992400.pdf (дата обращения: 29.09.2020).

\section{References}

1. Zhmur N. S. Tekhnologicheskiye i biokhimicheskiye protsessy ochistki stochnykh vod na sooruzheniyakh s aerotenkami [Technological and biochemical processes of wastewater treatment at facilities with aeration tanks]. Moscow, AKVAROS Publ., 2003. 512 p.

2. Martsul' V. N. Regulatory legal regulation of sludge handling in sewage treatment plants. Materialy Mezhdunarodnoy konferentsii, posvyashchennoy 145-letiyu UP "Minskvodokanal" "Sovremennyye tendentsii $v$ razvitii vodosnabzheniya $i$ vodootvedeniya" [Materials of the international conference, dedicated to the 145th anniversary of the UE "Minskvodokanal" "Modern trends in the development of water supply and sanitation"]. Minsk, 2019, pp. 195-200 (In Russian).

3. Ignatenko A. V. Biosorption-biocoagulation detoxification of waste water by active sludge. Trudy $B G T U$ [Proceedings of BSTU], 2015, no. 4: Chemistry, Organic Substances Technology and Biotechnology, pp. 262-266 (In Russian).

4. PND F 12.15.1-08. Guidelines for sampling for wastewater analysis. Moscow, FBU FTsAO Publ., 2015. 45 p. (In Russian).

5. Marchenko Z., Bal'tsezhak M. Metody spektrofotometrii v UF $i$ vidimoy oblastyakh $v$ neorganicheskom analize [Methods of spectrophotometry in the UV and visible ranges in inorganic analysis]. Moscow, Binom, Laboratoriya znaniy Publ., 2007. 714 p.

6. Klimov E. S., Buzaeva M. V. Prirodnyye sorbenty $i$ kompleksony v ochistke stochnykh vod [Natural sorbents and versenes in the treatment of wastewater]. Ul'yanovsk, UlGTU Publ., 2011. 201 p.

7. Ignatenko A. V. Sample preparation and biotesting of the toxicity of sewage sludge. Khimicheskaya bezopasnost' [Chemical safety], 2018, vol. 2, no. 2, pp. 251-271 (In Russian).

8. O nekotorykh voprosakh normirovaniya sbrosov khimicheskikh i inykh veshchestv v sostave stochnykh vod: postanovleniye Ministerstva prirodnykh resursov i okhrany okruzhayushchey sredy Resp. Belarus' ot 26.05.2017 № 16 [On some issues of regulation of discharges of chemical and other substances in the composition of wastewater: Decree of Council of the Ministry of Natural Resources and Environmental Protection of the Republic of Belarus, 26.05.2017, no. 16]. Available at: https://pravo.by/upload/docs/op/W217321 41_1497992400.pdf (accessed 29.09.2020).

\section{Информация об авторах}

Игнатенко Аркадий Васильевич - кандидат биологических наук, доцент, доцент кафедры биотехнологии. Белорусский государственный технологический университет (220006, г. Минск, ул. Свердлова, 13a, Республика Беларусь). E-mail: ignatenko_av@tut.by

Масехнович Александра Андреевна - магистрант кафедры биотехнологии. Белорусский государственный технологический университет (220006, г. Минск, ул. Свердлова, 13а, Республика Беларусь). E-mail: al.masekhnovich@mail.ru

\section{Information about the authors}

Ignatenko Arkadiy Vasil'yevich - PhD (Biology), Associate Professor, Assistant Professor, the Department of Biotechnology. Belarusian State Technological University (13a, Sverdlova str., 220006, Minsk, Republic of Belarus). E-mail: ignatenko_av@tut.by

Masechnovich Aleksandra Andreevna - Master's degree student, the Department of Biotechnology. Belarusian State Technological University (13a, Sverdlova str., 220006, Minsk, Republic of Belarus). E-mail: al.masekhnovich@mail.ru 